\title{
Joint Funds of the National Natural Science Foundation of China: a review of information sciences between 2011 and 2020
}

\author{
Zhilan $\mathrm{LI}^{1}$, Jinglin ZHANG ${ }^{1,2^{*}}$, Shijie ZHAO ${ }^{3}$, Quan LIU ${ }^{1}$, \\ Yan $\mathrm{WANG}^{1} \&$ Changrui WANG ${ }^{1}$ \\ ${ }^{1}$ National Natural Science Foundation of China, Beijing 100085, China; \\ ${ }^{2}$ School of Artificial Intelligence, Hebei University of Technology, Tianjin 210021, China; \\ ${ }^{3}$ School of Automation, Northwestern Polytechnical University, Xi'an 710072, China
}

Received 11 July 2021/Accepted 30 July 2021/Published online 25 November 2021

Citation Li Z L, Zhang J L, Zhao S J, et al. Joint Funds of the National Natural Science Foundation of China: a review of information sciences between 2011 and 2020. Sci China Inf Sci, 2021, 64(12): 227101, https://doi.org/ $10.1007 / \mathrm{s} 11432-021-3357-8$

The National Natural Science Foundation of China (NSFC) fully introduces and implements a strict and objective international peer review system and performs its mission of supporting basic research, cultivating talents, conducting international cooperation, and promoting economic and social development, which is the main channel to promote social and economic development. From the perspective of the funding source of basic research funds, China's basic research funds mainly rely on the financial allocation of governments at all levels. The funding source is still relatively single, whereas other innovative countries have diversified funding sources, with corporate capital accounting for a significant proportion. In 2013, government allocations accounted for about $43 \%$ of basic research funding in the UK, allocations from companies accounted for about $23 \%$, and donations from charities and overseas funds accounted for $34 \%$. In 2015, the federal government allocations accounted for $44 \%$ of basic research spending in the United States, corporations accounted for $28 \%$, and the universities accounted for $12 \%$. Other nonprofit organizations accounted for $13 \%$, and state governments for $3 \%$.

Presently, the NSFC has 18 types of funding projects, in which the Joint Funds are essential parts of the scientific funding system. The Joint Funds are mainly composed of Fostering Program projects, Key Program projects and Integrated projects [1]. From 2011 to 2020, the Joint Funds increased from 369 million CNY to 2.39 billion CNY, with an average annual growth of 225 million CNY. Meanwhile, the number of funded projects increased from 344 to 1084, with an average annual growth of 82 projects per year, as shown in Figure S1. Due to the leading role of the NSFC in supporting basic research, the Joint Funds have attracted the attention of more scientists and researchers. In the past ten years, information science has been one of the most significant Joint Funds supported fields [2]. Therefore, this study aims to analyze the projects of the information science field funded by the NSFC's Joint Funds between 2011 and 2020. Data analysis was also performed to seek out these regularities or trends in Joint Funds of NSFC [2].

The Joint Funds were established by the NSFC with local governments, scientific research institutions, and enterprises to address the key scientific issues during social development. The Joint Funds fully reflect the role of NSFC in guiding and integrating social resources and basic research, promoting the cooperation of relevant departments, industries, regions, universities, and research institutions [3]. Additionally, the Joint Funds cultivate scientific and technological talents, which support China's innovative development in various research fields.

From 2011 to 2020, 6965 applications were approved by the NSFC from 41142 Joint Funds projects. The overall funding information of Joint Funds from 2011 to 2020 is presented in Table S1. Meanwhile, the NSFC received 4634 applications for information science projects and funded 964 of the information science projects from the Joint Funds. As illustrated in Figure S2, 438 Fostering Program projects, 514 Key Program projects, 6 Center projects, and 6 Integrated projects in the information science field were funded by the NSFC. Table S2 presents the detailed funding information in the information science field. Meanwhile, 964 projects from 7 different subfields of information science have been funded. Table S3 lists Joint Funds projects supported in the information science field from 2011 to 2020 according to the scientific area code. Table S4 presents the number of projects funded by 14 different types of Joint Funds in the information science field.

- Supporting institutions. From 2011 to 2020, there were 964 projects funded in the information science field, which were based on 177 host organizations. Figure S3 shows the top ten institutions established in the Fostering Program

\footnotetext{
* Corresponding author (email: jinglin.zhang37@gmail.com)
} 
projects, while Figure S4 shows the top ten institutions established in the Key Program projects. Figure S5 shows the distribution of approved funding projects by geographic region. Between 2011 and 2020, applicants from 24 provinces and municipalities received funding projects.

- Applicant's professional qualifications. Funded applicants ranged in age from 26 to 65 , and the 31-55 years old applicants received the most projects, as shown in Figure S6. Among the applicants funded by Key Program projects, 141 have senior titles, such as professors and researchers, and 4 have associate senior titles, such as associate professors. Among the applicants who received the Fostering Program, 84 have senior titles, such as professors and researchers, 98 have associate senior titles, such as associate professors, and 19 have intermediate titles, such as lecturers and assistant researchers. Detailed information is illustrated in Figure S7. Collaboration is one of the essential features to win the Joint Funds. Of these, 351 funded projects involved collaborations between three institutions, while 366 funded projects involved partnerships between two institutions. Detailed information on projects collaboration is illustrated in Figure S8.

Discussion. Some salient features of the Joint Funds have been determined from the online data analysis, which provides new insights for future funding layout and funding application.

(1) Joint Funds support almost every field of information science research, like computer applications, artificial intelligence, electronics and communications, cyber security, and biomedical engineering.

(2) Interagency cooperation is also popular among NSFC Joint Funds applications. Most of the approved Fostering Program applicants are aged between 31 and 45, and the approved Key Program applicants are aged between 31 and 55 , which suggests that most of the principal investigators are productive around their $40 \mathrm{~s}$.

(3) Qualified applicants are expected to have a rich academic experience, academic ability, and team leadership ability. The project proposal must be prepared in strict accordance with the Joint Funds application guidelines.

Since 2019, the NSFC has strengthened top-level design and forward-looking basic research support based on the principle of national needs and diversified investment guidance, focusing on core scientific issues in key areas. To promote resource sharing and multiparty cooperation, the NSFC focuses on major scientific issues in emerging interdisciplinary fields, addressing the issues in urgent need of regions, industries, and enterprises. Joint Funds mainly focus on fundamental scientific issues, the integration of different disciplines, and the importance of cooperation and connection with other national science projects. The candidates of Joint Funds should have adequate preparation and research conditions, creative ability, and a high-level academic leader to implement these Joint Funds projects.

To this end, the NSFC established National Natural Science Foundation Regional Innovation and Development Joint Funds, and Enterprise Innovation and Development Joint Funds with cosponsors to gradually develop the joint funding system, to further improve the efficiency of funds distribution $[2,4]$. In the new period of scientific funds, the National Natural Science Foundation Regional Innovation and Development Joint Funds have attracted great attention and policy support from local governments. Presently,
23 provinces, autonomous regions, and municipalities have joined the National Natural Science Foundation Regional Innovation and Development Joint Funds, including Sichuan, Hunan, Anhui, Jilin, Heilongjiang, Liaoning, Hebei, Guangdong, Hubei, Beijing, Zhejiang, Chongqing, Qinghai, Tibet, Ningxia, Guangxi, Shanxi, Fujian, Henan, Gansu, Inner Mongolia, Hainan, and Shandong. In total, 23 provinces, autonomous regions, and municipalities propose the planned investment with 7.57 billion CNY in the next five years. Simultaneously, 2.52 billion $\mathrm{CNY}$ will be matched by the NSFC, amounting to a total of 9.805 billion CNY. Meanwhile, eight enterprises, including China Petroleum and Chemical Corporation, China National Offshore Oil Corporation, China Electronics Science and Technology Corporation, China Aerospace Science and Technology Corporation, China Guangdong Nuclear Power Group Co., China Mobile Communications Corporation, State Grid Corporation of China, and China Southern Power Grid Co., have joined the National Natural Science Foundation Enterprise Innovation and Development Joint Funds. These enterprises plan to invest 1.89 billion CNY in the next five years, while the NSFC funds 0.48 billion CNY with a total of 2.37 billion CNY.

Simultaneously, the NSFC steadily strengthens cofinanced work with industry agencies and follows up cooperation with the China Academy of Engineering Physics, China Civil Aviation, Ministry of Water Resources, China Three Gorges Corporation, State Power Investment Group Co., Ltd., and China Meteorological Administration. In the new period, a total of 2.25 billion CNY will be invested by the above agencies, and 0.59 billion $\mathrm{CNY}$ will be matched by the NSFC, for a total of 2.84 billion CNY.

The future plan. The NSFC plans to accelerate the establishment of a joint funding system with higher funding efficiency, encourage society and individuals to donate to basic research, and promote diversified investment in society. Through the guiding role of the Joint Funds, scientific research guided by the interests of scientists will gradually be employed to solve the needs of local governments, enterprises, and industries. The NSFC will explore the establishment of a complete and diversified demand-oriented funding system. The NSFC will continue to improve funding allocation efficiency, strengthen the scientific management and evaluation of Joint Funds projects, optimize the mechanism of guideline formation, and encourage support innovation.

Supporting information Figures S1-S8 and Tables S1-S4. The supporting information is available online at info.scichina. com and link.springer.com. The supporting materials are published as submitted, without typesetting or editing. The responsibility for scientific accuracy and content remains entirely with the authors.

\section{References}

1 NSFC. NSFC Annual Guidance Books in 2011, 2012, 2013 , 2014, 2015, 2016, 2017, 2018, 2019, 2020. http://www.nsfc. gov.cn/english/site_1/funding/E1/2018/07-09/112.html

2 NSFC. NSFC Annual Report in 2011, 2012, 2013, 2014, 2015, 2016, 2017, 2018, 2019, 2020. http://www.nsfc.gov. cn/english/site_1/report/C1/2018/10-18/130.html

3 Lei R, Zhang J, Zhou H, et al. Analysis of population health projects funded by Joint Fund of the National Natural Science Foundation of China between 2015 and 2019 . Ann Transl Med, 2020, 8: 1477-1477

4 Liu Y, Gao Z, Wang H, et al. Analysis of projects funded by the National Natural Science Foundation of China during the years of 2014-2018. Ann Transl Med, 2019, 7: 267-267 